\title{
Effects of survivin on FVADT chemotherapy for refractory multiple myeloma
}

\author{
HUA YANG, XINGJUN DU and YUREN XI
}

Department of Hematology, The Second Affiliated Hospital of Zhengzhou University, Zhengzhou, Henan 450014, P.R. China

Received March 31, 2015; Accepted April 29, 2016

DOI: 10.3892/etm.2016.3401

\begin{abstract}
The present study aimed to investigate the effects of survivin, an apoptosis inhibitor protein, on the efficacy of the fludarabine, vincristine, epirubicin, dexamethasone and thalidomide (FVADT) chemotherapy regime for the treatment of refractory multiple myeloma (MM). A total of 82 patients with MM were selected from the Hematology Inpatient Department at The Second Affiliated Hospital of Zhengzhou University (Zhengzhou, China). The initial treatment group consisted of 40 patients with MM, who received the vincristine, epirubicin and dexamethasone (VAD) chemotherapy regime. The refractory group consisted of 42 patients with refractory MM, who received the FVADT chemotherapy regime. Bone marrow biopsies were collected via marrow aspirations, and the protein expression of survivin was analyzed by immunohistochemistry. In addition, the Kaplan-Meier method was used for survival analyses. Intergroup differences in the protein expression levels of survivin were compared, and the association between survivin expression and the short- and long-term effects of FVADT chemotherapy were analyzed. The positive expression rate of survivin was significantly higher in the refractory group, as compared with the initial treatment group $(\mathrm{P}<0.05)$. Furthermore, the complete remission rate and the effective rate were significantly lower in the survivin-positive group, as compared with the survivin-negative group $(\mathrm{P}<0.05)$. The overall survival, progression free survival and 1 and 3 year survival rates of the survivin-positive group were significantly higher, as compared with the survivin-negative group $(\mathrm{P}<0.05)$. The results of the present study suggested that the protein expression of survivin was upregulated in refractory MM tissues, which was indicative of a poor short- and long-term efficacy for FVADT chemotherapy.
\end{abstract}

Correspondence to: Dr Hua Yang, Department of Hematology, The Second Affiliated Hospital of Zhengzhou University, 2 Jingba Road, Zhengzhou, Henan 450014, P.R. China

E-mail: huayanghn@163.com

Key words: apoptosis inhibitory protein, survivin, refractory multiple myeloma, FVADT chemotherapy

\section{Introduction}

Multiple myeloma (MM), which is a malignant tumor of plasma cells undergoing clonal proliferation, accounts for $10 \%$ of hematological malignancies (1). The incidence of MM is increasing yearly (2). Chemotherapy is an important therapeutic option for MM (3). The standard chemotherapy drugs are fludarabine, vincristine, epirubicin, dexamethasone and thalidomide (FVADT) (4). Fludarabine, which is the cytotoxic analogue of deoxyadenosine phosphate (a metabolite in normal cells), can be used as an effective antitumor drug and has demonstrated significant clinical efficacy in the treatment of chronic lymphocytic leukemia (5). Thalidomide can improve the growth and drug-resistance status of tumor cells by inhibiting the growth and adherence of myeloma cells or bone marrow stromal cells (6). Early chemotherapy regimes had low complete remission (CR) rates and high recurrence rates; however, the effects of chemotherapy on MM have improved with the development of chemotherapy drugs and treatment technology (7). Previous studies have demonstrated that $50-70 \%$ patients with $\mathrm{MM}$ are sensitive to chemotherapy drugs $(7,8)$. However, following multiple chemotherapies, drug-resistance and refractory MM may develop (9). Refractory MM is defined by the presence of MM following initial treatment and 2-3 courses (1 month/course) of vincristine, table adriamycin and dexamethasone (VAD) or melphalan and prednisone (MP) chemotherapy, with no observed effect or partial remissions associated with relapses following treatment and a remission time of $<2$ months (10). The concentration change of clonal memory B lymphocytes in the MM cell cycle may influence the recurrence and risk of MM (11). Therefore, the clearance of B lymphocytes may improve the chemotherapeutic efficacy and prognosis of MM.

Survivin is a member of the inhibitor of apoptosis protein family, and has been shown to specifically target caspase to inhibit apoptosis (12). Therefore, survivin has functions in controlling cell differentiation and inhibiting apoptosis (13). Previous studies have demonstrated that survivin is overexpressed in the majority of tumor cells and shows no expression in normal tissues $(14,15)$. The alteration of survivin expression in malignant tissues and the clinical significance of survivin have attracted attention due to its anti-apoptosis effects and specific expression in tumor tissue (16). Furthermore, previous studies have shown that survivin is closely associated with drug-resistance, chemotherapy efficacy and prognosis $(17,18)$. 
However, few previous studies have investigated the effects of survivin on the efficacy of FVADT chemotherapy for the treatment of refractory MM.

\section{Subjects and methods}

Subjects. A total of 82 patients with MM who underwent FVADT chemotherapy at the The Second Affiliated Hospital of Zhengzhou University (Zhengzhou, China) were selected for inclusion in the present study between January 2010 and January 2011. All patients met the diagnostic criteria for MM (19). Of the 82 cases, 40 were cases of newly diagnosed MM (initial treatment group) and 42 were cases of refractory MM (refractory group). The initial treatment group consisted of 24 males and 16 females, with an age range of 44-67 years and a mean age of $55.41 \pm 8.34$ years. A total of 20 patients in the initial treatment group had an immunoglobulin $(\mathrm{Ig}) \mathrm{G}(\mathrm{K} / \lambda)$ tumor type, 12 had an IgA (K/ $\lambda)$ tumor type, and eight had a light chain $(\mathrm{K} / \lambda)$ tumor type (20). In 18 cases, the Durie-Salmon (DS) stage was II (A/B), whereas it was III (A/B) for the remaining 22 cases (21). Furthermore, the International Staging System (ISS) (22) stage was I in 12 cases, II in 19 cases and III in 9 cases. The refractory group was composed of 25 males and 17 females, with an age range of 45-68 years and a mean age of $56.18 \pm 8.19$ years. In 21 patients, the tumor type was $\operatorname{IgG}(\mathrm{K} / \lambda)$, whereas 13 had an $\operatorname{IgA}(\mathrm{K} / \lambda)$ tumor type and eight had a light chain $(\mathrm{K} / \lambda)$ tumor type. The DS stage was II (A/B) in 19 cases and III (A/B) in the remaining 23 cases. The ISS stage was I in 14 cases, II in 18 cases and III in 10 cases. The age, gender, type, DS stage and ISS stage were not significantly different between the two groups $(\mathrm{P}>0.05)$. The present study was conducted in accordance with the Declaration of Helsinki (23), and with approval from the Ethics Committee of the Second Affiliated Hospital of Zhengzhou University. Written informed consent was obtained from all participants.

Treatment. Patients in the refractory group were treated with FVADT chemotherapy between 2 and 6 times for 14-42 days. The dosage of fludarabine (Flu; Haizheng Pharmaceutical Co., Hangzhou, China) was $25 \mathrm{mg} / \mathrm{m}^{2}$ from the first to the third day, vincristine (VCR; Wanle Pharmaceutical Co., Shenzen, China) was $0.5 \mathrm{mg} / \mathrm{m}^{2}$ from the first to the fourth day, adriamycin (A; Antibiotics S.P.A., Milan, Italy) was $12 \mathrm{mg} / \mathrm{m}^{2}$ from the first to the fourth day, dexamethasone (D; Furen Pharmaceutical Co., Zhengzhou, China) was $20 \mathrm{mg} / \mathrm{m}^{2}$ from the first to the fourth day and thalidomide (T; Changzhou Pharmaceutical Co., Changzhou, China) was $20 \mathrm{mg} / \mathrm{m}^{2}$ once every night. The conventional toxicity grading criteria of the US National Cancer Institute served as a reference for assessing the drug side-effects (24). When adverse reactions were above grade III, the dosage was gradually tapered to $50-150 \mathrm{mg}$ once every night. Drugs were withdrawn until disease progression occurred. Patients in the initial treatment group were treated with VAD chemotherapy. The dosage of VCR was $0.5 \mathrm{mg} / \mathrm{m}^{2}$ from the first to the fourth day, A was $12 \mathrm{mg} / \mathrm{m}^{2}$ from the first to the fourth day and D was $20 \mathrm{mg} / \mathrm{m}^{2}$ from the first to the fourth day.

Immunohistochemistry. Bone marrow was collected for marrow biopsies. Streptavidin-peroxidase (SP), rabbit anti-human survivin monoclonal antibody and SP immunoassay kits (cat. no. 0007) were purchased from Fuzhou Maixin Biotechnology Company (Fuzhou, China) and used according to the manufacturer's protocols. Briefly, marrow biopsies were fixed in $40 \mathrm{~g} / 1$ paraformaldehyde at room temperature for $30 \mathrm{~min}$, incubated in $3 \%$ peroxide solution at room temperature for $10 \mathrm{~min}$ and mounted. Subsequently, the biopsies were incubated in goat serum (Sijiqing, Hangzhou, China) at $37^{\circ} \mathrm{C}$ for $15 \mathrm{~min}$, followed by incubation overnight at $4^{\circ} \mathrm{C}$ with rabbit anti-human monoclonal survivin (1:200 dilution; cat. no. LC-C105516; LifeSpan Biosciences, Inc., Denver, CO, USA). Subsequently, marrow biopsies were incubated with biotin-conjugated goat anti-rabbit secondary antibody (1:200 dilution; cat. no. BA1003; Wuhan Boster Biological Technology, Ltd., Wuhan, China) at $37^{\circ} \mathrm{C}$ for $10 \mathrm{~min}$, and then incubated at $37^{\circ} \mathrm{C}$ for $10 \mathrm{~min}$ with horseradish peroxidase-labeled streptavidin (1:500 dilution; cat. no. BA1081; Wuhan Boster Biological Technology, Ltd.). After washing with phosphate-buffered saline (PBS), 3,3'-diaminobenzidine was used as the chromogenic reagent. Finally, the biopsies were stained with hematoxylin and mounted with neutral gum. A control group was incubated with PBS instead of primary antibody. Survivin-positive and survivin-negative groups were identified by microscopy (AX80; Olympus Corporation, Tokyo, Japan).

Observation indexes. The color of the cytoplasm (pale yellow or brown) was noted following immunohistochemistry and 500 tumor cells per marrow biopsy were observed under a high power microscope (AX80; Olympus Corporation). A percentage of positive cells in the tumor cells of $>10 \%$ was considered positive expression, whereas $\leq 10 \%$ positive cells was considered negative expression, according to a previous study (25).

The short-term clinical efficacy, which was assessed using the European Cooperative Group for Bone Marrow Transplantation criteria (26), was divided into CR, partial response (PR), stable disease (SD) and progressive disease (PD). The treatment efficiency was defined as follows: Treatment efficiency $=C R+P R$.

The long-term clinical efficacy was assessed over a 4-year period by integrated follow-up procedures, including telephone communication and outpatient and home visits. The time at which the patient succumbed to the disease was considered as the end of follow-up. Survival analysis included overall survival (OS; the period from disease diagnosis to the time at which the patient succumbed to the disease) and progression-free survival (PFS; the period from the initial treatment to disease progression or the time at which the patient succumbed to the disease).

Statistical analysis. Data were analyzed using SPSS 18.0 software (SPSS, Inc, Chicago, IL, USA). Measurement data were analyzed using Student's t-test and are expressed as the mean \pm standard deviation. Count data were analyzed by the $\chi^{2}$ test. Survival analyses were performed using the Kaplan-Meier test. $\mathrm{P}<0.05$ was considered to indicate a statistically significant result.

\section{Results}

Comparison of survivin-positive expression rates. As shown in Table I and Fig. 1, compared with the initial treatment group, the survivin-positive expression rate was significantly higher in the refractory group, and the survivin-negative 
Table I. Comparison of survivin-positive expression rate in both groups [Case (\%)].

\begin{tabular}{lccc}
\hline & & \multicolumn{2}{c}{ Survivin } \\
\cline { 3 - 4 } Group & Cases & Positive & Negative \\
\hline Initial treatment group & 40 & $17(42.50)$ & $23(57.50)$ \\
Refractory group & 42 & $30(71.43)$ & $12(28.57)$ \\
$\chi^{2}$ & & 6.01 & \\
P-value & & $<0.05$ & \\
& &
\end{tabular}

Table II. Association between survivin expression and the chemotherapy efficacy in patients with multiple myeloma.

\begin{tabular}{lcccccc}
\hline Group & Cases & CR & PR & SD & PD & $\begin{array}{c}\text { Efficacy } \\
\text { rate }(\%)^{\mathrm{a}}\end{array}$ \\
\hline $\begin{array}{l}\text { Survivin- } \\
\text { positive group }\end{array}$ & 47 & 2 & 8 & 20 & 17 & 21.28 \\
$\begin{array}{l}\text { Survivin- } \\
\text { negative group }\end{array}$ & 35 & 6 & 14 & 8 & 7 & 57.14 \\
$\begin{array}{l}\chi^{2} \\
\text { P-value }\end{array}$ & & & & & & \\
\hline
\end{tabular}

${ }^{\text {aT }}$ The $\mathrm{CR}$ rate is included in the efficacy rate. $\mathrm{CR}$, complete remission; $\mathrm{PR}$, partial response; $\mathrm{SD}$, stable disease; $\mathrm{PD}$, progressive disease.

Table III. Association between survivin expression and the chemotherapy efficacy of FVADT.

\begin{tabular}{lcccccc}
\hline Group & Cases & CR & PR & SD & PD & $\begin{array}{c}\text { Efficacy } \\
\text { rate }(\%)^{\mathrm{a}}\end{array}$ \\
\hline $\begin{array}{l}\text { Survivin- } \\
\text { positive group }\end{array}$ & 30 & 1 & 5 & 15 & 9 & 20.00 \\
$\begin{array}{l}\text { Survivin- } \\
\text { negative group }\end{array}$ & 12 & 2 & 7 & 2 & 1 & 75.00 \\
$\begin{array}{l}\chi^{2} \\
\text { P-value }\end{array}$ & & & & & & \\
\hline
\end{tabular}

${ }^{\text {aTh }} \mathrm{CR}$ rate is included in the efficacy rate. FVADT, fludarabine, vincristine, epirubicin, dexamethasone and thalidomide; CR, complete remission; $\mathrm{PR}$, partial response; $\mathrm{SD}$, stable disease; $\mathrm{PD}$, progressive disease.

expression rate was significantly lower in the refractory group $(\mathrm{P}<0.05)$. Furthermore, the survivin-negative expression rate was significantly lower in the refractory group, as compared with the initial treatment group $(\mathrm{P}<0.05)$.

Association between survivin expression and the short-term efficacy of chemotherapy. As shown in Table II, the CR rate and treatment efficacy were significantly lower in the survivin-positive sub-group, as compared with the
Table IV. Association between survivin expression and prognosis of patients with refractory multiple myeloma.

\begin{tabular}{lccc}
\hline Group & Cases & OS (month) & PFS (month) \\
\hline $\begin{array}{l}\text { Survivin- } \\
\text { positive group }\end{array}$ & 47 & $29.64 \pm 8.17$ & $18.76 \pm 4.62$ \\
$\begin{array}{l}\text { Survivin- } \\
\text { negative group }\end{array}$ & 35 & $48.06 \pm 10.35$ & $36.01 \pm 5.13$ \\
T-value & & & \\
P-value & & 5.42 & 6.01 \\
\hline
\end{tabular}

Data are presented as the mean \pm standard deviation or $\mathrm{n}$. OS, overall survival; PFS, progression-free survival.

Table V. Association between survivin expression and prognosis of MM patients treated with FVADT chemotherapy.

\begin{tabular}{lccc}
\hline Group & Cases & OS (month) & PFS (month) \\
\hline $\begin{array}{l}\text { Survivin- } \\
\text { positive group }\end{array}$ & 30 & $28.65 \pm 7.05$ & $19.06 \pm 5.04$ \\
$\begin{array}{l}\text { Survivin- } \\
\text { negative group }\end{array}$ & 12 & $39.67 \pm 11.24$ & $35.88 \pm 8.25$ \\
$\begin{array}{l}\text { T-value } \\
\text { P-value }\end{array}$ & & 6.25 & 5.87 \\
\hline
\end{tabular}

Data are presented as the mean \pm standard deviation or $\mathrm{n}$. MM, multiple myeloma; FVADT, fludarabine, vincristine, epirubicin, dexamethasone and thalidomide; OS, overall survival; PFS, progression-free survival.

survivin-negative sub-group, irrespective of the stage of cancer and chemotherapy used $(\mathrm{P}<0.05)$. Similarly, for the refractory group only, the CR rate and treatment efficacy were significantly lower in the survivin-positive sub-group, as compared with the survivin-negative sub-group $(\mathrm{P}<0.05$; Table III).

Association between survivin expression and the long-term efficacy of chemotherapy. As shown in Table IV, the OS and PFS of the survivin-positive sub-group were significantly higher, as compared with the survivin-negative sub-group $(\mathrm{P}<0.05)$, irrespective of the stage of $\mathrm{MM}$ and chemotherapy regime administered. In addition, for the refractory group only, the OS and PFS were significantly higher for the survivin-positive sub-group, as compared with the survivin-negative sub-group $(\mathrm{P}<0.05$; Table V). A Kaplan-Meier survival analysis of the refractory MM patients treated with FVADT chemotherapy indicated that the 1 and 3-year survival rates of the survivin-positive group were significantly higher, as compared with the survivin-negative group $(\mathrm{P}<0.05$; Fig. 2).

\section{Discussion}

At present, diagnosis and treatment strategies for MM have achieved satisfactory efficacy (27). Although autologous hematopoietic stem cell transplantation has significantly improved 

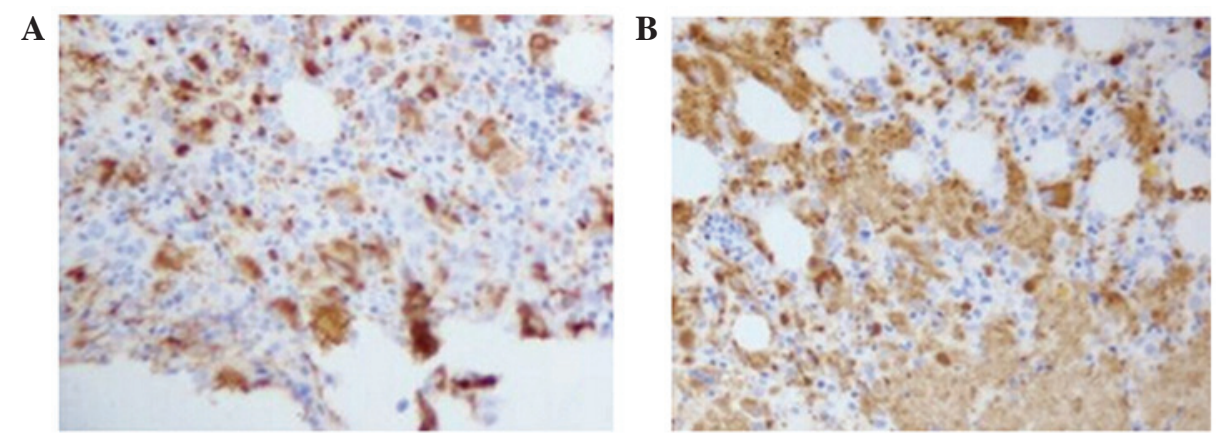

Figure 1. Survivin immunohistochemistry. (A) Initial treatment group. (B) Refractory group.

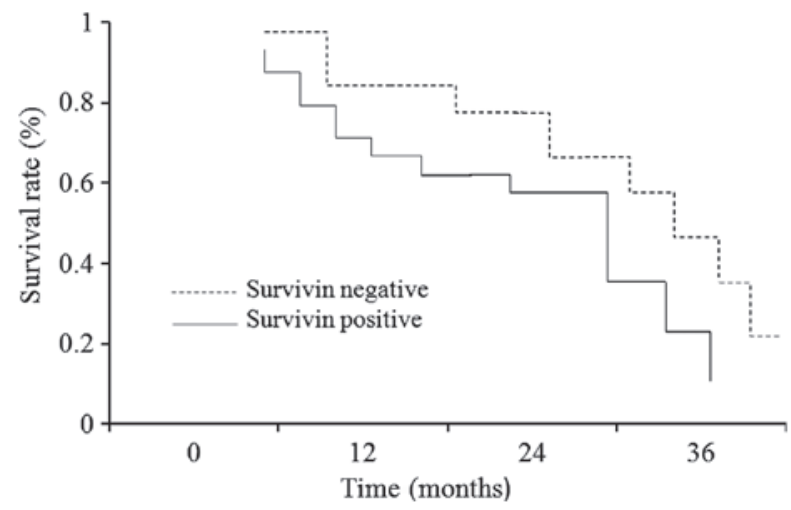

Figure 2. Comparison of overall survival rate in the survivin-negative and survivin-positive groups.

the treatment of MM, it can only be applied to patients with $\mathrm{MM}<65$-years-of-age who are able to tolerate surgery (28). Therefore, the majority of patients with MM require an effective chemotherapy regimen. Flu, which specifically targets lymphocytes, can prevent the growth of a tumor by inhibiting KM3 cell proliferation in patients with MM and by regulating cell autocrine interleukin signaling (29). In addition, Flu has been shown to improve the prognosis of patients with refractory MM (30). T is used as an angiogenesis inhibitor by prohibiting the mechanisms of cell growth and reproduction in myeloma cells (31). In addition, $\mathrm{T}$ has been shown to reduce the epidermal growth factor level in, limit the blood supply to and inhibit the cell proliferation of MM, as well as directly inhibiting the growth and reproduction of MM and stromal cells (6). Furthermore, $\mathrm{T}$ has been shown to promote apoptosis by regulating the expression of cell surface adhesion molecules and altering the biological activity of MM by affecting the secretion of cytokines from MM and stromal cells (32). In addition, $\mathrm{T}$ has a regulatory role on $\mathrm{T}$ lymphocytes (11). FVADT chemotherapy, which combines the effects of Flu and $\mathrm{T}$, has been shown to enhance the inhibition of MM cells (33). However, few previous studies have investigated the effects of biological markers on the efficacy of FVADT chemotherapy for the treatment of patients with refractory MM.

Survivin is an important member of the inhibitor of apoptosis protein family that is located on human chromosome 17, region q25 (12). The survivin gene, which is $14.7 \mathrm{~kb}$ in length, encodes an 142 amino acid cytoplasmic protein that has a molecular weight of $16.5 \mathrm{kD}$. Survivin has been shown to inhibit cell apoptosis, alter cell proliferation and regulate tumor angiogenesis $(34,35)$. Survivin is highly expressed in tumor tissues and cells, whereas it is not usually expressed in mature undifferentiated tissues (36). The effects of survivin on FVADT chemotherapy in patients with refractory MM requires further clinical discussion.

The present study demonstrated that the survivin-positive expression rate was significantly higher in the refractory group, as compared with the initial treatment group. Refractory MM refers to patients with MM that, following initial treatment and 2-3 courses of VAD or MP chemotherapy, show no signs of improvement or only partial remission ( $<2$ months) that is susceptible to relapse. Patients with refractory MM are challenging to cure and have a poor prognosis (37). Previous studies have demonstrated that survivin has an important role in anti-apoptosis signaling by inhibiting the activity of caspase- 3 and caspase-7 $(38,39)$. The apoptosis index of survivin-positive tumors is low and has been associated with a poor prognosis (40). The above factors lead to a significant increase in survivin-positive expression in refractory MM tissues. In the present study, the CR and efficacy rates were significantly lower in the survivin-positive group, as compared with the survivin-negative group, whereas the OS, PFS and 1 and 3-year survival rates were significantly higher in the survivin-positive group, as compared with the survivin-negative group. These results suggested that survivin had a significant predictive value in the immediate and long-term efficacy of using FVADT chemotherapy for the treatment of patients with refractory MM, and that its positive expression may be considered an indicator for poor prognosis of MM chemotherapy. Oto et al (41) reported positive survivin expression for all acute myeloid leukemia (AML) lines in a comparative study of survivin expression in patients with AML and patients with AML who were initially treated. Another study reported positive survivin expression in $65 \%$ of initially treated AML tissues (42). Survivin expression has been closely associated with white blood cell count and clinical classification (43). In addition, the survival period of patients with positive survivin expression was significantly shorter, as compared with that of survivin-negative patients, and the former had earlier and higher recurrence rates and a poor prognosis (41). Therefore, positive survivin expression may be a risk factor of poor prognosis in patients with AML. Furthermore, Tsubaki et al (44) demonstrated that survivin-positive patients had a shorter survival by evaluating the expression of survivin in diffuse large B-cell lymphoma and the prognosis. This suggested that 
positive survivin expression may be used as a poor prognostic marker for diffuse large B cell lymphoma. Survivin expression has also been closely associated with the prognosis of patients with blood malignancies, in which survivin-positive patients typically have a poor prognosis (45). The present study demonstrated that survivin expression may also be used as a valuable indicator of immediate and long-term prognoses of patients with blood malignancies, such as MM. The positive expression of survivin in patients with refractory MM was high, and the immediate and long-term prognosis of survivin-positive patients was improved, as compared with survivin-negative patients.

In conclusion, the present study demonstrated that the positive protein expression rate of survivin was significantly increased in refractory MM tissues, and that this was indicative of a reduced short- and long-term curative efficacy of FVADT chemotherapy.

\section{References}

1. Scott K, Hayden PJ, Will A, Wheatley K and Coyne I: Bortezomib for the treatment of multiple myeloma. Cochrane Database Syst Rev Apr 4: CD010816, 2016.

2. Vélez R, Turesson I, Landgren O, Kristinsson SY and Cuzick J: Incidence of multiple myeloma in Great Britain, Sweden, and Malmö, Sweden: The impact of differences in case ascertainment on observed incidence trends. BMJ Open 6: e009584, 2016.

3. Lu J: The changes in the multiple myeloma diagnostic criteria and its impact on treatment. Zhongguo Zhong Liu Lin Chuang 21: 819-822, 2014 (In Chinese).

4. Dong W, Cai JH, Yang H and Zhai X: Clinical efficacy of FVADT in the treatment of multiple myeloma. Guangdong Yi Xue 32: 1746-1748, 2011 (In Chinese).

5. Lee JW, Kang HJ, Kim S, Lee SH, Yu KS, Kim NH, Jang MK, Kim H, Song SH, Park JD, et al: Favorable outcome of hematopoietic stem cell transplantation using a targeted once-daily intravenous busulfan-fludarabine-etoposide regimen in pediatric and infant acute lymphoblastic leukemia patients. Biol Blood Marrow Transplant 21: 190-195, 2015.

6. Bolomsky A, Schreder M, Meißner T, Hose D, Ludwig H, Pfeifer $\mathrm{S}$ and Zojer N: Immunomodulatory drugs thalidomide and lenalidomide affect osteoblast differentiation of human bone marrow stromal cells in vitro. Exp Hematol 42: 516-525, 2014.

7. Willan J, Eyre TA, Sharpley F, Watson C, King AJ and Ramasamy K: Multiple myeloma in the very elderly patient: Challenges and solutions. Clin Interv Aging 11: 423-435, 2016.

8. Maiso P,Huynh D, Moschetta M, Sacco A, Aljawai Y, Mishima Y, Asara JM, Roccaro AM, Kimmelman AC and Ghobrial IM: Metabolic signature identifies novel targets for drug resistance in multiple myeloma. Cancer Res 75: 2071-2082, 2015.

9. Amirshahrokhi K and Khalili AR: The effect of thalidomide on ethanol-induced gastric mucosal damage in mice: Involvement of inflammatory cytokines and nitric oxide. Chem Biol Interact 225: 63-69,2015.

10. Wang CL, He ZM, Zhou LT, Shi YY, Chen Y, Zhang L, Song L, Ding B and Liu DS: Effect of low-dose Lenalidomide in combination with Dexamethasone on refractory or relapsed multiple myeloma in the elderly. Zhong Nua Lao Nian Yi Xue Za Zhi 33: 1191-1193, 2014 (In Chinese).

11. Li X, Sun W, Jin F, Chen S, Zhong Y, Hu Y, Zhang J, An N, Shen M and Huang Z: Clinical observation of DECP combination chemotherapy for relapsing and refractory multiple myeloma patients with extramedullary plasmacytomas. Zhonghua Yi Xue Za Zhi 94: 1258-1260, 2014 (In Chinese)

12. Chen X, Duan N, Zhang C and Zhang W: Survivin and tumorigenesis: Molecular mechanisms and therapeutic strategies. J Cancer 7: 314-323, 2016.

13. Sun L, Zhao Y, Shi H, Ma C and Wei L: LMP-1 induces survivin expression to inhibit cell apoptosis through the NF- $\kappa \mathrm{B}$ and $\mathrm{PI} 3 \mathrm{~K} /$ Akt signaling pathways in nasal NK/T-cell lymphoma. Oncol Rep 33: 2253-2260, 2015.
14. Sokołowska J, Urbańska K, Giziński S, Wysocka A, Cywińska A and Lechowski R: Survivin expression in canine lymphomas in relation with proliferative markers. Pol J Vet Sci 18: 113-122, 2015.

15. Bobustuc GC, Patel A, Thompson M, Srivenugopal KS, Frick J, Weese J and Konduri SD: MGMT inhibition suppresses survivin expression in pancreatic cancer. Pancreas 44: 626-635, 2015.

16. Kasamatsu J, Takahashi S, Azuma M, Matsumoto M, Morii-Sakai A, Imamura M, Teshima T, Takahashi A, Hirohashi Y, Torigoe T, et al: PolyI:C and mouse survivin artificially embedding human $2 \mathrm{~B}$ peptide induce a CD4+ $\mathrm{T}$ cell response to autologous survivin in HLA-A*2402 transgenic mice. Immunobiology 220: 74-82, 2015.

17. Hernandez JM, Farma JM, Coppola D, Hakam A, Fulp WJ, Chen DT, Siegel EM, Yeatman TJ and Shibata D: Expression of the antiapoptotic protein survivin in colon cancer. Clin Colorectal Cancer 10: 188-193, 2011.

18. Yu CJ, Ou JH, Wang ML, Jialielihan N and Liu YH: Elevated survivin mediated multidrug resistance and reduced apoptosis in breast cancer stem cells. J BUON 20: 1287-1294, 2015.

19. Rajkumar SV: Evolving diagnostic criteria for multiple myeloma. Hematology Am Soc Hematol Educ Program 2015: 272-278, 2015.

20. Su YT, Xie XS, Sun H, Ma J, Wan DM and Liu YF: Clinical Features of 46 Multiple Myeloma Patients with Different Renal Pathology. Zhongguo Shi Yan Xue Ye Xue Za Zhi 24: 487-491, 2016 (In Chinese).

21. Deng SH, Xu Y, Mai YJ, Wang YF, Zhao YZ, Zou DH and Qiu LG: Analysis of the international staging system of multiple myeloma and its comparison with the DS and IFM staging system in 122 Chinese patients. Zhonghua Xue Ye Xue Za Zhi 29: 217-21, 2008 (In Chinese).

22. Ooi MG, de Mel S and Chng WJ: Risk stratification in multiple myeloma. Curr Hematol Malig Rep 11: 137-147, 2016.

23. Ndebele P: The Declaration of Helsinki, 50 years later JAMA 310: 2145-2146, 2013

24. Dueck AC, Mendoza TR, Mitchell SA, Reeve BB, Castro KM, Rogak LJ, Atkinson TM, Bennett AV, Denicoff AM, O'Mara AM, et al; National Cancer Institute PRO-CTCAE Study Group: Validity and reliability of the US National Cancer Institute's patient-reported outcomes version of the common terminology criteria for adverse events (PRO-CTCAE). JAMA Oncol 1: 1051-1059, 2015.

25. El Deeb NM and Abdelzaher E: Stem cell markers OCT4 and nestin in laryngeal squamous cell carcinoma and their relation to survivin expression. Pathol Res Pract 210: 751-758, 2014.

26. Lanza F, Campioni DC, Hellmann A, Milone G, Wahlin A, Walewski J, Spedini P, Fiamenghi C, Cuneo A, Knopińska W, et al: Individual quality assessment of autografting by probability estimation for clinical endpoints: A prospective validation study from the European group for blood and marrow transplantation. Biol Blood Marrow Transplant 19: 1670-1676, 2013.

27. Rajkumar SV and Kumar S: Multiple myeloma: Diagnosis and treatment. Mayo Clin Proc 91: 101-119, 2016.

28. Wang Y, Xu P, Chen Y, Fan Q, Li J, Zhao W, Mi J and Yan H: Novel agent induction therapy alone or followed by autologous stem cell transplantation in younger patients with multiple myeloma: A single-center retrospective study of 114 cases. Mol Clin Oncol 4: 107-113, 2016.

29. Yang CM, Meng HT, Liu H and Qian WB: Effects of fludarabine on apoptosis and gene expression profile in multiple myeloma cells. Zhonghua Xue Ye Xue Za Zhi 31: 659-662, 2010 (In Chinese)

30. Gozzetti A, Candi V, Fabbri A, Schiattone L, Cencini E, Lauria F, Frasconi A, Crupi R, Raspadori D, Papini G, et al: Chemoimmunotherapy with oral low-dose fludarabine, cyclophosphamide and rituximab (old-FCR) as treatment for elderly patients with chronic lymphocytic leukaemia. Leuk Res 38: 891-895, 2014

31. Gao Y, Ma G, Liu S, Teng Y, Wang Y and Su Y: Thalidomide and multiple myeloma serum synergistically induce a hemostatic imbalance in endothelial cells in vitro. Thromb Res 135: 1154-1159, 2015.

32. Anderson KC: Moving disease biology from the lab to the clinic. Cancer 97 (Suppl): 796-801, 2003.

33. Slawinska-Brych A, Zdzisinska B, Mizerska-Dudka M and Kandefer-Szerszen M: Induction of apoptosis in multiple myeloma cells by a statin-thalidomide combination can be enhanced by p38 MAPK inhibition. Leuk Res 37: 586-594, 2013. 
34. El-Aarag BY, Kasai T, Zahran MA, Zakhary NI, Shigehiro T, Sekhar SC, Agwa HS, Mizutani A, Murakami H, Kakuta H and Seno M: In vitro anti-proliferative and anti-angiogenic activities of thalidomide dithiocarbamate analogs. Int Immunopharmacol 21: 283-292, 2014.

35. Athanasoula KCh, Gogas H, Polonifi K, Vaiopoulos AG, Polyzos A and Mantzourani M: Survivin beyond physiology: Orchestration of multistep carcinogenesis and therapeutic potentials. Cancer Lett 347: 175-182, 2014.

36. Wang L, Kang Y, Zheng W, Li L, Shi L and Ma X: Effect on apoptosis and cell cycle of recombinant double negative dominant mutation Survivin (T34/117A) in breast cancer cell B-Cap-37. Biomed Pharmacother 68: 277-284, 2014.

37. Majithia N, Vincent Rajkumar S, Lacy MQ, Buadi FK, Dispenzieri A, Gertz MA, Hayman SR, Dingli D, Kapoor P, Hwa L, et al: Outcomes of primary refractory multiple myeloma and the impact of novel therapies. Am J Hematol 90: 981-985, 2015.

38. Fukuda S, Foster RG, Porter SB and Pelus LM: The antiapoptosis protein survivin is associated with cell cycle entry of normal cord blood CD34(+) cells and modulates cell cycle and proliferation of mouse hematopoietic progenitor cells. Blood 100: 2463-2471, 2002.

39. Poomsawat $\mathrm{S}$, Punyasingh $\mathrm{J}$ and Vejchapipat P: Overexpression of survivin and caspase 3 in oral carcinogenesis. Appl Immunohistochem Mol Morphol 22: 65-71, 2014.
40. Tsubaki M, Takeda T, Ogawa N, Sakamoto K, Shimaoka H, Fujita A, Itoh T, Imano M, Ishizaka T, Satou T and Nishida S: Overexpression of survivin via activation of ERK1/2, Akt and $\mathrm{NF}-\kappa \mathrm{B}$ plays a central role in vincristine resistance in multiple myeloma cells. Leuk Res 39: 445-452, 2015.

41. Oto OA, Paydas S, Tanriverdi K, Seydaoglu G, Yavuz S and Disel U: Survivin and EPR-1 expression in acute leukemias: Prognostic significance and review of the literature. Leuk Res 31: 1495-1501, 2007.

42. Huang J, Lyu H, Wang J and Liu B: Influence of survivin-targeted therapy on chemosensitivity in the treatment of acute myeloid leukemia. Cancer Lett 366: 160-172, 2015.

43. Adida C, Recher C, Raffoux E, Daniel MT, Taksin AL, Rousselot P, Sigaux F, Degos L, Altieri DC and Dombret H: Expression and prognostic significance of survivin in de novo acute myeloid leukaemia. Br J Haematol 111: 196-203, 2000.

44. Tsubaki M, Komai M,Itoh T,Imano M, Sakamoto K, Shimaoka H, Takeda T, Ogawa N, Mashimo K, Fujiwara D, et al: By inhibiting Src, verapamil and dasatinib overcome multidrug resistance via increased expression of Bim and decreased expressions of MDR1 and survivin in human multidrug-resistant myeloma cell. Leuk Res 38: 121-130, 2014.

45. Chen S, Wang Y, An L, Fei ZT and Li T: The diagnostic value of survivin in malignant pleural effusion: A meta-analysis. Clin Chim Acta 441: 142-147, 2015. 